\section{PASTEUR AS ILLUSTRATION OF MODERN} SCIENCE.

Apart from the inspiring promises and hopes of high science, every one should realize clearly the direct practical value to be derived in the daily intercourse of each with nature, from a correct knowledge, of even the most elementary, of the laws of this world in which we are striving to live happily.

It is true that the advocates of scienceteaching can adduce other, perhaps far nobler grounds, in pointing out the high and symmetrical development, which the study of science gives to the human intellect and the unfailing well-spring of pure pleasure which it affords.

But many of the older men now in power, having never had any accurate training in science, can scarcely appreciate such arguments, and if capable of being reached at all, it must be by proofs the most cogent of the unfailing utility of elementary science, and the stupendous wealth producing power of high science.

We cannot any longer afford to let children grow up ignorant of all that is going on around us in this beautiful world, without learning to use eyes and reasoning powers, because their parents may know nothing accurately of the laws of physical, but above all, of mental health.

Fundamental principles and their commoner applications must now be universally taught, if only to let every one realize how now our modern science stands ready to aid, to save, to satisfy, endangered or craving bodies or minds.

Nor is it only to the mature mind that the study of science is a pleasure. It has been well said that nothing is more beautifully characteristic of young children than the desire to know the why and wherefore of everything they see. This natural spirit of inquiry needs only proper direction and fostering care to give us great scientists, men who, like Pasteur, confer uncounted millions of actual physical wealth on the country or state so fortunate as to be honored by their presence.

The great practical difficulty, however, in regard to giving science the place every one is beginning to see belongs to it, in elementary as well as advanced education, is that it requires for success, teachers of far higher order than those usually employed to drum into young heads the dry old school routine. No one can teach science who does not know it. And for a teacher to have the true informing spirit to vivify his book knowledge, it is found almost uniformly essential that he should have been in direct personal contact with some one of those great men whose joy it is to be able to advance the age in which they live, and lead on mankind to unexpected victories in the progressive conquest of the universe.

To get our brightest young people so to qualify themselves, it is needful they should understand the surpassing dignity of science and science teaching; that in fact, of late years, not only surprising discoveries are coming on in crowds, but that whole new sciences of world-remaking power are springing into existence around us. As one illustration from many, take what has been called bacteriology.

It is only a little more than 20 years ago that the publication of Pasteur's papers on alcoholic fermentation gave the first sound basis for the idea that fermentation was caused by a micro-organism.

It is now demonstrated that all fermentations of this class are due to the development of micro-organisms, and that bacteria are most important factors in nature, being the chief agents by which the complex organic constituents of plants and animals are brought back to simple forms capable of serving again as food for plants.

Following closely on Pasteur's early publications, and as a direct result of them, we 
have the great revolution in surgery brought about by Sir Joseph Lister, which has enlarged the whole scope of the science, and is daily saving hundreds of lives.

Besides the vast increase in our knowledge of the mode of spead of infective disease, successful experiments have been carried on by Pasteur on the attenuation of virus and the conversion of virulent microorganisms into useful vaccines.

And perhaps one could not choose a more readily understood illustration of the wealth conferred on his whole nation by a man of science than is furnished by a recapitulation of some of the things accomplished by Pasteur. Having discovered exactly what fermentation is, he was able, by a few simple directions, to almost entirely put an end to the spoiling of beer by secondary fermentation and the souring of wines by the transformation of alcohol into acid.

This sounds rather unimportant, but some idea of its commercial value may be obtained when it is remembered that there are about 45 departments of France that make wine, and there was a known loss yearly of wine to the extent of one million seven hundred thousand francs in four departments. Since Pasteur's method has been applied, there has been saved of this loss at least one million five hundred thousand francs annually. This is for four departments. As there are in France about 45 departments that make wine, you may approximately estimate the stupendous saving.

Again the farmers and stockmen of France were visited by a terrible and increasing cattle plague, the malignant pustule, or black quarter of cattle and sheep, which killed annually thousands of horses and oxen and hundreds of thousands of sheep. There seemed no hope for them. But Pasteur found by a series of researches not only that this disease was caused by a specific minute organism, but that he could save the ani- mals from contagion by inoculating them with attenuated germs obtained by artificial cultivations made in special liquids.

The figures from the official statement indicating the ravages made by this disease in France alone for the years 1882 and 1883 are 2,196 horses, 62,107 oxen, 538,245 sheep.

When we learn that the average mortality was reduced by Pasteur's inoculations in the proportion of 10 to 1 for sheep, and 15 to 1 for oxen, cows and horses, some idea may be grasped of his vast and continuous gift of wealth to his country in actual solid meat-beef and mutton.

Again, another disease has reduced the silk-worm industry to a most deplorable condition. In three departments in the center of France, after the silk-worm disease had attacked the factories, the product yielded a value of less than one million five hundred thousand francs.

But Pasteur came to the rescue, discovered the micro-organism, conquered it, and since the regulations laid down by him have been applied, the average value per annum, calculated on five years, in those departments has risen to more than twenty-two million francs.

After such facts as that, who can wonder at those sentences from Huxley: "I weigh my words when I say that if the nation could purchase a potential Watt, or Davy, or Farraday, at the cost of a hundred thousand pounds down, he would be dirt cheap at the money. It is a mere commonplace and everyday piece of knowledge, that what these three men did has produced untold millions of wealth, in the narrowest economical sense of the word."

But let no one suppose that these men or any other of the immortal scientists would have been satisfied even by producing untold millions of wealth. They all had higher aims and made higher achievements.

From such men and from science comes 
a progressive betterment of human character, the final, the most precious result of evolution on this earth.

\section{George Brdce Halsted.} Austin, Texas.

\section{DETERMINATION OF THE CONSTANTS OF THE DIURNAL NUTATION.}

(1) In the Annuaire de l'Observatoire Royal de Belgique for 1894, I gave the following results deduced from Gyldén's observations of the latitude of Pulkova:

Let $\kappa=$ constant of annual aberration,

$\kappa^{\prime}=$ reduced constant of systematical aberration,

i. e., projected on the equator, which I derived from my terms of the second order which arise from the combination of annual and systematical aberrations.*

$\tilde{a}=$ parallax of Polaris;

$v=$ Peters's constant of nutation $9^{\prime \prime} .2235$;

$\boldsymbol{n}=$ the correction of this constant;

$v^{\prime}=$ Peters's constant of the term $\cos 2 \odot: 0^{\prime \prime} .555$;

$n^{\prime}=$ its correction;

$\nu=$ the constant of the diurnal nutation;

$\mathrm{L}==$ the longitude of the first meridian,

i. e., the meridian which passes through the axis of the moment of inertia $A$ of the solid crust of the globe.

Applying my formula, M. Byl, astronomer adjunct at the Royal Observatory of Belgium, has found

$$
\begin{aligned}
& \tilde{a}=20^{\prime \prime} .408 . \kappa^{\prime}=39^{\prime \prime} . \omega=0^{\prime \prime} .0546 . \\
& n=0^{\prime \prime} .003 . n^{\prime}==-0^{\prime \prime} .0444 . \\
& v=0^{\prime \prime} .0665 . \mathrm{L}=12^{\mathrm{h}} 0^{\mathrm{m}} \text { E. from Pulkova. }
\end{aligned}
$$

Mlness has prevented M. Byl from coördinating his calculations, and I was compelled to make a new determination of both the last constants for the next volume of the Annales de l' Observatoire Royal de Belgique.

(2) My purpose was to make use of the excellent series of observations of the Polaris in $Z R$ made at Dorpat by F. W. Struve,

* Catéchisme correct d'astronomie sphérique (Memorie della Pontificia Accademia dei nuovi Lincei, Roma. Vol. IX.), and Annuaire de l'Observatoire Royal de Belgique pour 1894, p. 346. a series which had led me to conclude that the Eulerian period of 305 days was too short.*

In order to eliminate the variations of latitude, I have only used half of the sum of $R$ observed at consecutive upper and lower transits. The laborious calculation of the whole series has given me unexpected results: $\nu=0^{\prime \prime} .17$, twice or threefold too great; $L=12^{\mathrm{h}} 10^{\mathrm{m}} \mathrm{E}$. from Pulkova, good result; $n^{\prime}=+0^{j} .045$, which is in complete discordance with the value $n^{\prime}=-0^{\prime \prime} .0444$ deduced from Nyrén's observations, and moreover, theoretically inadmissible. In seeking the cause of these unlooked-for results, I found that an error of sign I had noted down some years ago and considered as a simple typographical error has been used by Peters in all his reductions of Struve's observations. In his formulæ (p. 13 of Numerus Constans nutationes) he wrote with + , instead of - the terms of nutation in $2 \odot$, and calculated his reductions with this erroneous sign.

All my work had to be done over again, as will be the case for Peters's determination of the constant of nutation.

In order to eliminate this serious error I used Struve's residuals, corrected by increasing by $0 .{ }^{\prime \prime} 2$ the Delambre's constant he had used for his reductions, and to avoid the other errors of reduction I have formed the differences between successive pairs of observations chosen so that the coefficients $\Sigma_{1}$ and $\Sigma_{2}$ were sufficiently different in both pairs.

(3) The diurnal nutation in $A$ is in the meridian

$$
\Delta a=-\operatorname{tg} \delta\left(\xi \Sigma_{2}+\eta \Sigma_{1}\right),
$$

where $v=v \sin (2 \mathrm{~L}+a), \eta=v \cos (2 L+a)$; we may write

$$
\Delta a=x \Sigma_{2}+y \Sigma_{1}=a x+b y .
$$

The principal terms I have used for the calculation of $a\left(\Sigma_{2}\right)$ and $b\left(\Sigma_{1}\right)$ are

* Annuaire de l'Observatoire Royal de Belgique pour 1891. 